\title{
Ankara İmrahor Vadisi ve İncesu Deresinin Biyofilik Tasarım Yaklaşımı İçinde Değerlendirilmesi
}

\author{
İzel Gökten ${ }^{1}$ iD Abdullah Kelkit ${ }^{2 *}$ iD \\ ${ }^{1}$ ÇOMÜ, Lisansüstü Eğitim Enstitüsü, Peyzaj Mimarlığı ABD, Çanakkale \\ ${ }^{2}$ ÇOMÜ, Mimarlık ve Tasarım Fakültesi, Peyzaj Mimarlığı Bölümü, Çanakkale \\ *Sorumlu yazar: akelkit@comu.edu.tr
}

Geliş Tarihi: 08.12.2020

Kabul Tarihi: 10.05.2021

$\ddot{\mathbf{O z}}$

Gelişen teknolojiyle birlikte insan ile doğa arasındaki temel bağın zamanla kaybolduğu görülmektedir. Doğadan uzaklaşmış bir yaşam çevresi fiziksel ve zihinsel sağlık problemlerine neden olmaktadır. Vadiler, insan sağlığı ve yaşamı için mutlak gerekli olan doğa kavramının tam karşılığ1 niteliğindedir. Mikroklima koşulları yönünden diğer coğrafi şekillere göre önemli farklılıklara sahip olan vadiler, tarih boyunca yaşam, üretim ve yerleşim yeri olarak tercih edilmişlerdir. Çalışma, Ankara İmrahor Vadisi ve İncesu Deresi’nde yürütülmüştür. Çalışma alanında planlara aykırı uygulamaların gerçekleştiği, çevre koruma ve kullanım politikalarının yetersiz olduğu ve kentin getirdiği olumsuzluklar yüzünden doğal değerlerini kaybetme tehlikesiyle karşı karşıya kaldığ tespit edilmiştir. Çalışmada biyofilik tasarım yaklaşımı hedef alınarak insan ve doğa arasındaki kaybolan bağın yeniden kurulması amaçlanmıştır. Çalışma sonucunda İmrahor Vadisi'nin, biyofilik tasarım yaklaşımı ile kentleşmenin getirdiği psikolojik sorunlara karşı çözüm üretebileceği aynı zamanda halkın rekreasyonel ihtiyaçlarını karşılayabilen önemli potansiyellere sahip doğal bir yapı olduğu tespit edilmiştir. İnsan ve doğa arasındaki bağ temel alınarak biyofili kavram, tasarım ve planlama çalışmaları kapsamında biyofilinin 14 maddelik parametresi içinde İmrahor Vadisi ve İncesu Deresi değerlendirilmiştir. Değerlendirmeler sonucunda Peyzaj Mimarlığı bakış açısıyla çalışma alanına yönelik biyofilik planlama ve tasarım amaçlı çözüm önerileri getirilmiştir. Bu çalışma, Peyzaj Mimarlığı meslek disiplini açısından ülkemizde yapılan ilk örnek çalışmalardan biri olup bir kaynak niteliği taşımaktadır.

Anahtar Kelimeler: Ankara, Biyofilik Tasarım, İmrahor Vadisi, İncesu Deresi.

\section{Evaluation of Ankara Imrahor Valley nnd Incesu Stream Within Biophilic Design Approach Abstract}

With the advancing technology, it is seen that the basic connection between man and nature has disappeared over time. A living environment away from nature causes physical and mental health problems. Valleys are the exact equivalent of the concept of nature, which is necessary for human health and life. The valleys, which have significant differences compared to other geographical forms in terms of microclimate conditions, have been preferred as living, production, and settlement places throughout history. The study was carried out in Ankara Imrahor Valley and Incesu Stream. It has been determined that practices contrary to plans were realized in the study area, environmental protection and usage policies were insufficient, and the city faced the danger of losing its natural values due to the negativities brought by the city. The aim of the study is to reestablish the lost link between man and nature by targeting the biophilic design approach. As a result of the study, it has been determined that Imrahor Valley is a natural structure that can produce solutions to the psychological problems caused by urbanization with a biophilic design approach and at the same time meet the recreational needs of the people. Within the scope of biophile concept, design and planning studies based on the connection between human and nature, the Imrahor Valley and İncesu Creek were evaluated within the 14-item parameter of the biophile. As a result of the evaluations, biophilic planning and design solutions were proposed for the study area from the Landscape Architecture perspective. This study is one of the first exemplary studies conducted in our country in terms of the Landscape Architecture professional discipline and is a resource.

Key words: Ankara, Biophilic Design, Imrahor Valley, Incesu Stream 


\section{Giriş}

Biyofili kavramına göre insan içinde, tarihler boyu doğaya karşı duyulan ve sonradan öğrenilmeyen içsel bir bağ bulunmaktadır (Fromm, 1964; Wilson, 1984; Tilbury, 1995; Khan ve Peter, 1997; Kellert, 1997; Kellert, 2005). Günümüzün popüler yaşam alanları olarak bilinen modern kavramı adı altında teknoloji ve endüstriye dayalı olarak gelişen kent yapılarının artmasıyla birlikte insan ile doğa arasındaki temel bağ zamanla kaybolmuş ve insanın doğadan uzaklaşması kaçınılmaz olmuştur. Ankara ise, insan ve doğa arasındaki bağın kaybolmasının görüldüğü kent örneklerindendir. Çünkü teknolojik müdahaleler ile hızlı bir değişim süreci yaşamakta ve bu süreç içerisinde insanlara yapay ve sağlıksız bir çevrede yaşama zorunluluğu getirmektedir. Kentteki vadi sistemlerinin de doğal yapısı nüfus artışı, planlara aykırı ve denetimsiz çalışmalar yüzünden her geçen gün tahrip olmaktadır. Kent içinde bulunan doğal yapının zamanla yok olduğu görülen Ankara'da bulunan İmrahor Vadisi ve içinden geçen İncesu Deresi, bu duruma en iyi örnek olmuştur.

Zamanın teknolojisinde ketleşmenin getirdiği olumsuz etkileri iyileştiren, doğayı koruyan, sürdürülebilir, içinde biyoçeşitliliği barındıran, doğayla uyumlu tasarım ve planların gerçekleştiği bir kent olgusuna ihtiyaç doğmuştur (Davey, 2001). Tasarım, planlama ve yönetimde doğayı ön planda tutan biyofilik kentlerdir (Beatley, 2010). Bu yüzden zamanla doğal yapısını kaybetmiş alanların korunması, insan ve doğa arasındaki kaybolan bağın yeniden kurulması yeni bir yaklaşım olan biyofilik tasarım yaklaşımıyla gerçekleştirilmelidir. Kellert ve Calabrese (2015) tarafından, biyofilik tasarım, "kentsel yaşam ortamları yüzünden doğa ve insan arasındaki bozulan bağın yeniden kurulmasını sağlayarak, insanların sağlıklı olmalarını sağlayan, refah düzeylerini arttırmayı amaçlayan yaklaşım" olarak tanımlanmıştır. Bu durumda kent içinde biyofili kavramıyla planlanmış ve tasarlanmış yaşam alanlarına yer verilmesi önemli bulunmuştur.

$\mathrm{Bu}$ çalışmada kentin getirdiği olumsuzluklar yüzünden her geçen gün doğasının olumsuz etkilendiği, içerisinden bir akarsuyun geçtiği önemli potansiyellere sahip Ankara kentinde bulunan İmrahor Vadisi, biyofilik tasarım yaklaşımı içinde değerlendirilerek peyzaj mimarlığı bakış açısıyla incelenmiştir. Çalışma alanının bir vadi olmasının nedeni; biyofilik kent kavramı içinde insan sağlığı ve yaşamı için mutlak gerekli olan doğa kavramını karşılamasıdır. Aynı zamanda ekolojik, biyolojik ve mikroklima koşulları yönünden diğer coğrafi şekillere göre önemli bir farklılığa sahip olması ve vadilerin insan evrimi boyunca yaşam, konaklama, üretim ve yerleşim yeri olarak tercih edilmesinden dolayı çalışma alanı olarak seçilmiştir (Öztan, 2004). Vadi'ler bir taban ve iki yamaçtan oluşmaktadır. Vadi tabanında bulunan akarsu yatağı ile yamaçlar arasındaki yükseklik farkları vadi içerisinde hava akımlarına neden olmaktadır (Yılmaz, 2009). Akarsu vadileri, lokal hava akımı özellikleriyle diğer ekosistemlere göre farklı iklimsel karakterlere veya mikroklimaya sahiptirler (Şahin, 1996). Şahin'e (1996) göre, günün erken saatlerinde vadi tabanından, vadi yamaçlarına doğru hava akımı hareketi gerçekleşmektedir. Bu hareket vadilerde gece geç saatlerde tersine dönmektedir. Akşamüzeri ve gece geç saatlerde oluşan hava akımı hareketi ise, vadi tabanında bulunan akarsu boyunca bir akarsu kaynağına, bir akarsu ağızına doğru hareketlenmektedir (Şahin, 1996) (Şekil 1).
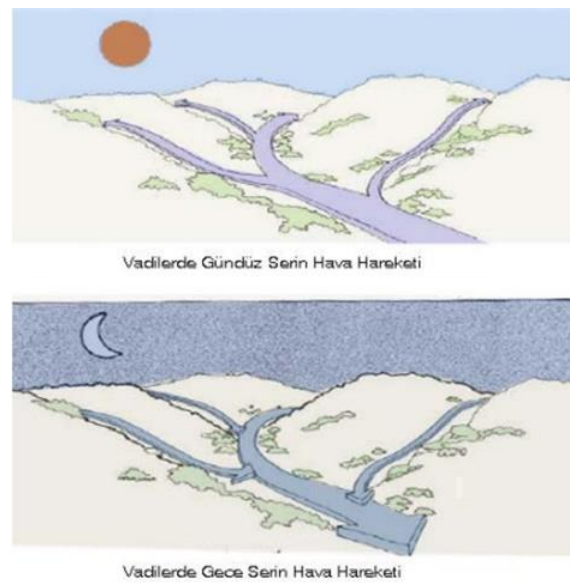

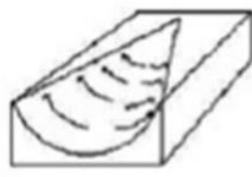

Sabah erken

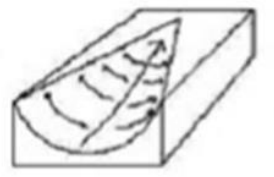

Aksam uzeri

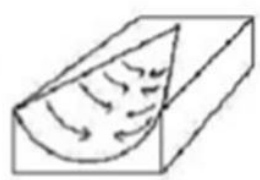

Gece

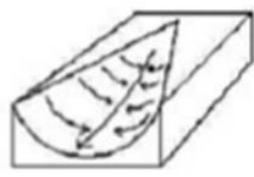

Gece gec saatler

Şekil 1. Günün değişen zamanlarında görülen vadi içi hava akımları (Robinette, 1983; Şahin, 1996) 
Vadilerde görülen gece ve gündüz rüzgar hareketleri kentlerdeki hava kirliliğinin önlenmesi açısından önemli bir yeri vardır. Kent üzerinde biriken kirli hava, vadilerde oluşan hava hareketleri ile kente doğru taşınır ve böylece kentteki hava kalitesi yükseltilmiş olmaktadır (Yılmaz, 2008). Kısacası kentlerdeki hava kalitesinin korunması ve sürekliliğinin sağlanması vadiler sayesinde olmaktadır. Vadiler, kirlenen kent havasının temizlenmesini sağlarken halkın rekreasyon ihtiyaçlarını karşılamakta, insan sağlığı ve yaşamı açısından hayati önem taşımaktadırlar.

Çalışma kapsamında biyofilik tasarım yaklaşımı ile ilgili pek çok teorik ve uygulama olmasına rağmen peyzaj mimarlığı meslek disiplini içinde İmrahor Vadisi'ne yönelik herhangi bir çalışmaya rastlanılmamıştır. Elde edilen bulgular dahilinde araştırma sonuç ve önerilerin başta peyzaj mimarlığ meslek disiplinine ve benzer peyzaj alanlarına rehber niteliğinde katkı sağlaması hedeflenmiştir.

\section{Materyal ve Yöntem \\ Materyal}

Çalışmanın ana materyalini; Ankara il sınırları içerisinde yer alan İmrahor Vadisi ve İncesu Deresi oluşturmaktadır. İmrahor Vadisi, Mamak ve Çankaya ilçe belediye sınırları içinde yer almaktadır. İçinde bulundurduğu endemik bitki türleri başta olmak üzere, İncesu Deresi, Eymir ve Mogan gölleri su sistemleriyle bağlantılı olmasıyla da önemli akarsu vadisi özelliklerine sahiptir ve aynı zamanda kent merkezine yakın bir bölgedir (Şekil 2).

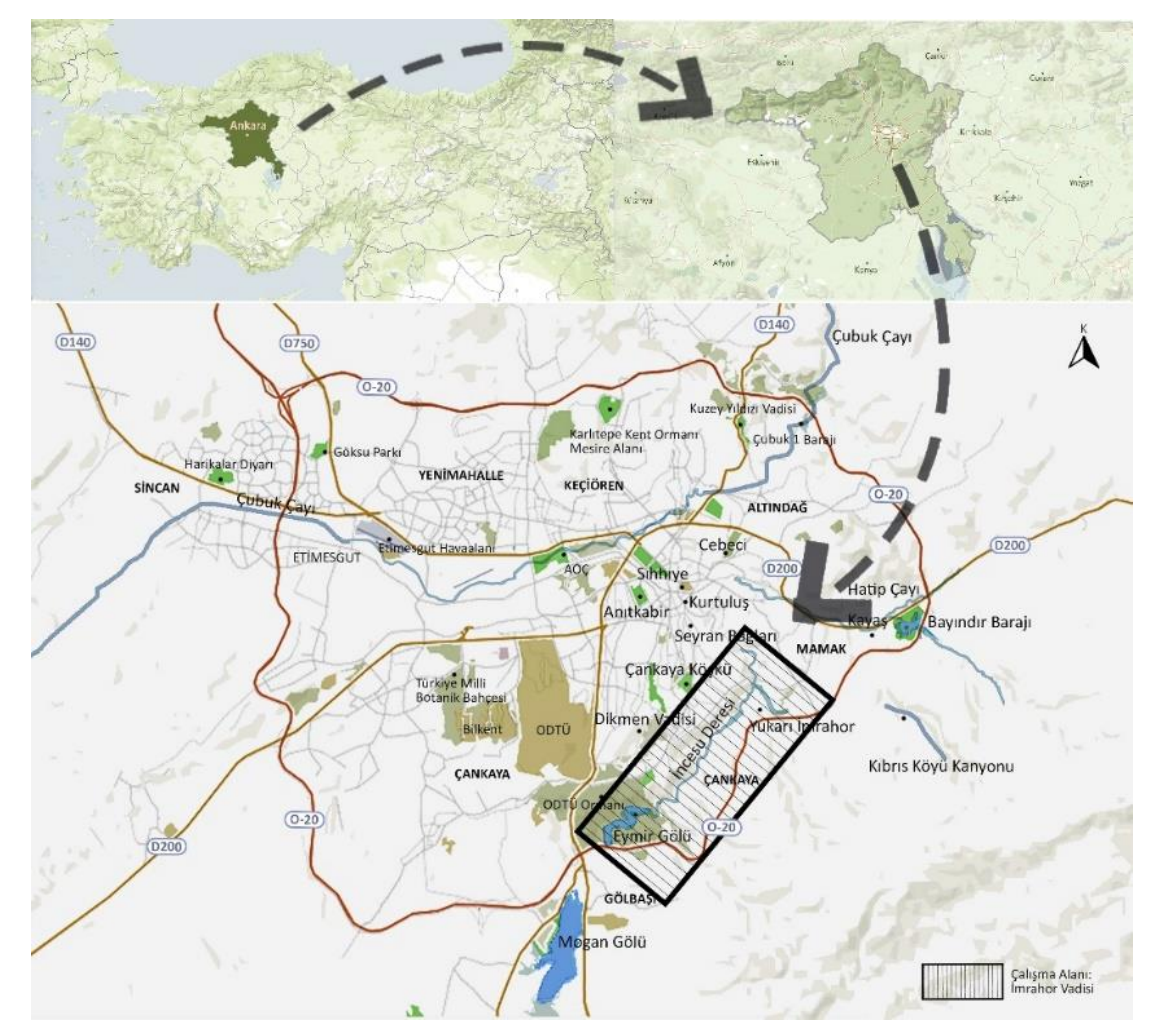

Şekil 2. Ankara İmrahor Vadisi ve yakın çevresi (Mapbox, 2020'den değiştirilerek)

Çalışma alanının Ankara İl merkezine uzaklığı 12,6 km'dir. Güneyinde Ankara Çevre Yolu, kuzeyinde İmrahor Köprüsü ve Doğukent Bulvarı ile sınırlanmaktadır. Kuzeydoğusunda 25-30 dk'lık mesafede Bayındır Barajı (Mavi göl) ve güneybatısında 15-20 dk'lık mesafede kalan Mogan ve Eymir Gölü bulunmaktadır. Ankara kent merkezinden gelen İmrahor Vadisi içerisinden geçip Eymir Gölü’ne kadar uzanan önemli ulaşım akslarına sahiptir. Diğer sahip olduğu ulaşım aksları Mühye köyü bağlantıları ve vadi içi ikinci derece yollardır. Ulaşımın oldukça kolay olması, kent ile ilişkisinin rahatça kurulması, bölgenin diğer önemli cazibe merkezlerine yakın olması nedeniyle yöre halkı tarafından tercih edilmesini sağlamaktadır. Bölgenin tarihi dokusuna bakıldığında eski tuğla fabrikalarının varlığı da tarihi bir öneme de sahip olduğunu göstermektedir. Ayrıca, paintball ve carting alanları ile mevcut bitki örtüsü ve hayvan varlığı da materyal olarak değerlendirilmiştir. 
İmrahor Vadisi'nin turizm ve ekonomik anlamda büyük bir potansiyele sahip olduğu öngörülmektedir. $\mathrm{Bu}$ anlamda bölgenin sahip olduğu potansiyeller açısından bilimsel yöntemlerle incelenmesi önem arz etmektedir. Zamanla yerleşim alanlarının artması ve gerçekleştirilen konutlaşma projeleri ile baskılanan İmrahor Vadisi'nin doğal değerlerini kaybettiği tespit edilmiştir. Sahip olduğu potansiyeller ve tehditler bakımından İmrahor Vadisi ve İncesu Deresi çalışma alanı olarak tercih edilmiştir. Bu çalışma, biyofilik tasarım yaklaşımı ile peyzaj mimarlığı meslek disiplini kapsamında İmrahor Vadisi'ndeki alan kullanımlarının değerlendirilmesini içermektedir.

Çalışma materyalini; çalışma alanı, çalışma alanına ait araç ve gereç, konuyla ilgili tanım, kavram ve kapsamı içeren geniş bir literatür çalışması, kitap, makale, yüksek lisans ve doktora tezleri ve bilimsel araştırma proje raporları, yazılı ve sözlü kaynaklar, imar planları ve imar planı tarihli açıklama raporları, yerinde gözlemler, haritalar, fotoğraflar ve uydu görüntüleri oluşturmaktadır.

\section{Yöntem}

Çalışmanın yöntemi; literatür araştırması, arazi gözlemi ve verilerin toplanması, veri inceleme, analiz edilme, verilerin değerlendirilmesi ve öneriler getirilmesi aşamalarından oluşmaktadır. $\mathrm{Bu}$ kapsamda 'Biyofilik Tasarım" yöntem olarak kullanılmıştır. Biyofilik Tasarım yaklaşımı ile alanın değerlendirilmesi aşamasında Kaya (2019)'nın çalışmasından yararlanılmıştır.

Çalışma alanında arazi gözlem ve çalışmaları gerçekleştirilmiştir. Biyofilik tasarım yaklaşımı ile alanda geniş bir inceleme ve değerlendirme gerçekleştirilmiştir. Bu değerlendirme ile birlikte çalışma alanın mevcut alan kullanımlarının biyofilik tasarım yaklaşımı ile belirlenmesi amaçlanmıştır. Son aşamada, alan kullanımlarının neler olması gerektiğine yönelik bir öneri listesi oluşturulmuştur. Gerçekleştirilen öneriler, peyzaj mimarlığı meslek disiplini planlama ve tasarım ilkeleri doğrultusunda biyofilik tasarım yaklaşımlı vadi içi alan kullanımına yöneliktir.

Çalışmanın değerlendirme aşamasında oluşturulan çizelge ile biyofilik tasarım yaklaşımı kapsamında alan üzerinden incelemeler yapılmıştır. Alanla ilgili biyofilik tasarım kavramına yönelik ilke ve öneriler oluşturulmuştur. $\mathrm{Bu}$ şekilde elde edilen yeni veriler değerlendirilerek sonuçlara varılmaya çalışılmıştır. Çalışma yöntemine ait biyofilik tasarım yaklaşımı ile alanın değerlendirilmesi aşaması aşağıdaki ayrıntılı bir şekilde açıklanmıştır.

İmrahor Vadisi için Browning ve ark. (2014) tarafından tanımlanan biyofilik tasarımın on dört parametresi kapsamında bir liste oluşturulmuş ve liste içinde mevcut alan kullanımları tek tek görselleri ile verilerek biyofilik tasarım yaklaşımı ile incelenmiştir. Liste içeriğinde seçilen alanın insan psikolojisi üzerindeki etkileri değerlendirilmiştir. Oluşturulan liste ile çalışma alanındaki tasarım unsurlarının varlığı tek tek sorgulanmış ve varlığı tespit edilen alanların uygulanabilirliği irdelenmiştir. Biyofilik tasarımın on dört parametresinin, peyzaj mimarlığı meslek disiplininde alansal uygulama ve faydaları üzerine bir rehber olması amaçlanmıştır. Seçilen alanın biyofilik sınıflandırma kapsamında incelenmesinden elde edilen bulguların başta peyzaj mimarlığı meslek disiplinine daha sonra İmrahor Vadisi'ne ne yönde faydalı olacağı tablodan görülmektedir.

Son aşamada, genel değerlendirme tablosunun verileri doğrultusunda elde edilen bulgular ile çalışma alanı olarak seçilen İmrahor Vadisi için kullanılabilecek bir biyofilik tasarım öneri listesi oluşturulmaya çalışılmıştır.

\section{Bulgular ve Tartışma}

\section{Biyofilik Tasarım Yaklaşımı ile Alanın Değerlendirilmesi}

Çalışma alanı, kenti çevreleyen vadiler sisteminin en önemli yeşil akslarından biridir. İmrahor Vadisi, kente temiz hava akımı sağlamak gibi büyük bir potansiyele sahip olmasına karşın gün geçtikçe vadi tabanları ve vadi yamaçlarında bu potansiyeli engelleyen projeler ile karşı karşıya kaldığ1 görülmektedir. Vadi'nin, biyofilik tasarım yaklaşımı ile kentleşmenin getirdiği psikolojik sorunlara karşı çözüm üretebileceği aynı zamanda halkın rekreasyon ihtiyaçlarını karşılayabilen önemli potansiyellere sahip doğal bir yapı olduğu düşünülmektedir. Bu düşünceden yola çıkarak çalışma alanı biyofilik tasarım yaklaşımına ait 14 tasarım parametresi Çizelge 2'de ayrıntılı bir şekilde incelenmiştir. Yapılan araştırmalar ve analizler sonucunda elde edilen bulgular bir bütün olarak değerlendirildiğinde seçilen çalışma alanı biyofilik tasarım anlayışıyla incelenmiştir. Biyofilik tasarımın 14 parametresi kapsamında incelenen listede bir çok parametre tespit edilmiştir. Bunun dışında eksikliği görülen ve tehlikede olan parametrelerin varlığı da dikkat çekmiştir. 
ÇOMÜ Zir. Fak. Derg. (COMU J. Agric. Fac.)

2021: 9 (1): 71-78

ISSN: 2147-8384 / e-ISSN: 2564-6826

doi: $10.33202 /$ comuagri. 837716

Çizelge 2. 14 Biyofilik Tasarım parametresi kapsamında çalışma alanı inceleme listesi

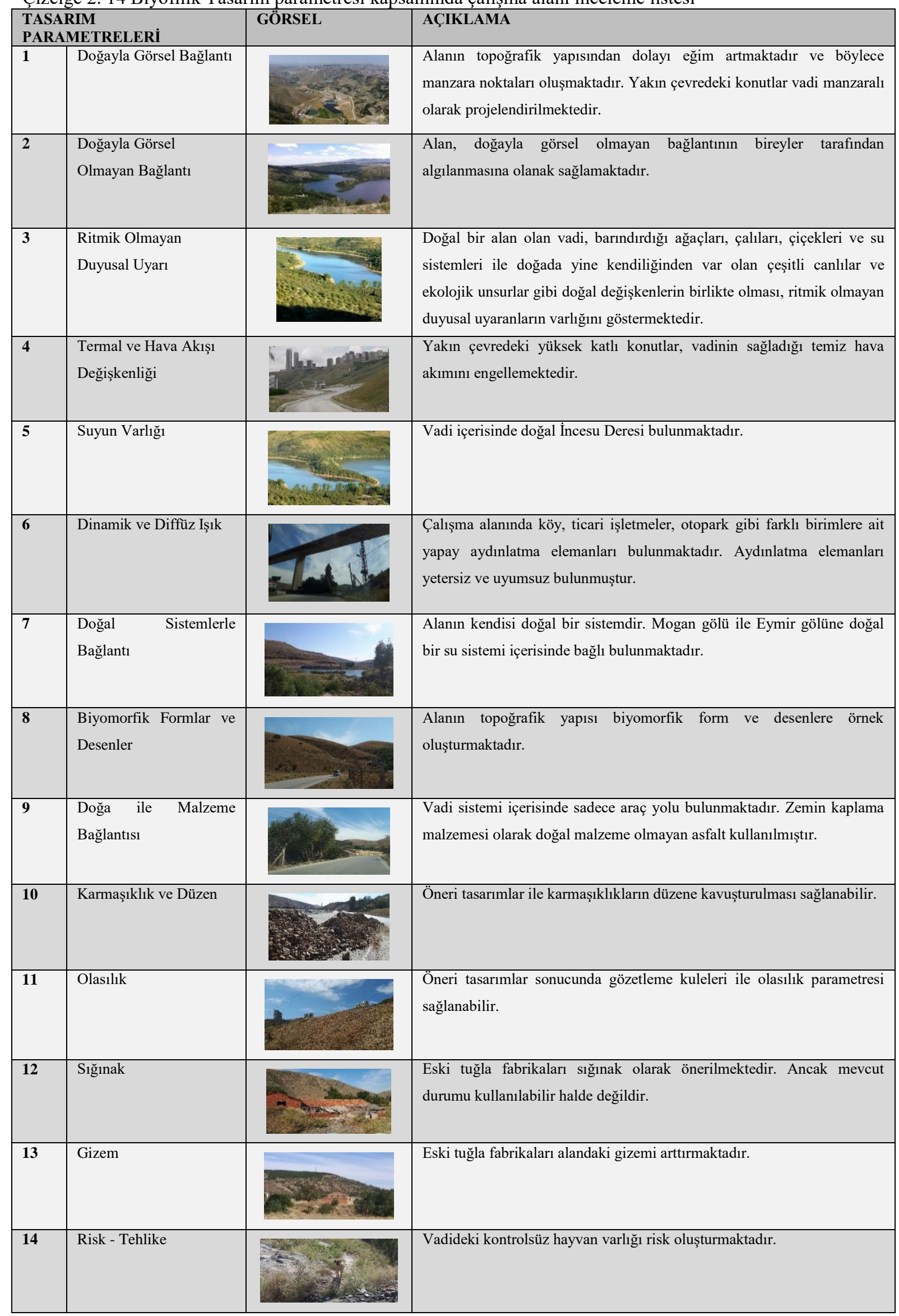


Biyofilik tasarım anlayışıyla İmrahor Vadisi'ne bakıldığında; çalışma alanında doğal sürecin devam ettiği fakat insan olgusuyla bir araya henüz gelemediği görülmektedir. Gün geçtikçe alandaki yapısal alanların kapladığı alan büyümekte, doğal alan azalmakta ve doğaya olan zarar artmaktadır. Bu durum biyofilik tasarım yaklaşımıyla çelişmektedir. Alanda karmaşık ve düzen, olasılık öğeleri bulunmamaktadır. Alandaki eski tuğla fabrikaları biyofilinin gizlilik ilkesini karşılamaktadır. Eski tuğla fabrikaları insanlar üzerinde geçmişe karşı merak uyandırmakta ve ilgi çekmekte, aynı zamanda gizem duygusunu harekete geçirmektedir. Önemli temiz hava koridorlarından biri olan İmrahor Vadisi, gerçekleştirilen konutlaşma projeleri ile biyofilinin termal ve hava akışı değişkenliğini engellemekte ve kentin mikroklimasını olumsuz yönde etkilemektedir. Alan içerisinde paintball, carting gibi geçici aktivite alanları bulunmaktadır. Çocukların doğayı deneyimleyebileceği doğal malzemelerle tasarlanmış aynı zamanda görme, dokunma, koklama ve duyma gibi duyu organlarının gelişimini sağlayan çocuk oyun alanlarına rastlanılmamıştır. Kısaca doğa içinde gerçekleşen ya da doğa temalı aktivite alanları bulunmamaktadır. Araç yolları dışında yaya yürüyüş ve gezinti yolları gibi ulaşım aksları da yer almamaktadır. Doğal malzemeli herhangi bir ulaşım aksına rastlanılmamıştır. Araç yollarının malzemesi ise asfalttır. Alanın genelinde koruma ve kullanım kararları alınmadığını söylemek mümkündür. Bundan dolayı biyofilideki doğal malzeme kullanımı ve sürdürülebilirlik ilkelerini karşılamamakta olduğu anlaşılmaktadır. Alanın bitkisel özellikleri incelendiğinde; endemik bitkilerin olduğu tespit edilmiştir. Fakat inşaat malzemelerinin çalışma alanı içine bilinçsizce depolanması başta endemik bitkiler Solanum cornutum Lam. (İtüzümü), Verbascum stachydifolium var. adspersum (Sı ̆̆ır kuyruğu), V. ancyritanum (Sı̆̆ır kuyruğu) ve V. stenostachyum (Sı ğır kuyruğu) olmak üzere diğer bitkilerin de zarar görmesine neden olmaktadır. Alandaki mevcut doğal bitki örtüsü ve İncesu Deresi'nin varlığı insanlar ve doğa arasındaki görsel ve görsel olmayan bağlantıyı kurmaktadır.

\section{Sonuç ve Öneriler}

Biyofiliyi temel alan ve doğanın iyileştirici gücünden yararlanan yurtiçi ve yurtdışı uygulama örnekleri bulunmakla birlikte ülkemizde bu konuda mimari ve iç mimarlık meslek disiplinlerinde uygulama çalışmalarına rastlanılmasına rağmen peyzaj mimarlığı meslek disiplinini ilgilendiren mekanlarda uygulanan başarılı bir çalışmaya rastlanılmamıştır. $\mathrm{Bu}$ durumun en önemli sebepleri; meslek çalışmalarının ve eğitim kurumlarının müfredatlarının bu konuda yetersiz oluşu, çalışan meslek gruplarının konu hakkındaki bilgi eksikliği ile birlikte tasarımlar gerçekleştirilmesi, karar verici ve uygulayıcı mekanizmalarca peyzaj alanlarına yeterli önem verilmemesi, halkın doğanın iyileştirici gücü ve doğa koruması gibi konulardaki bilinç eksikliğinin bulunması vb sayılabilir. $\mathrm{Bu}$ konuda bilincin yükseltmesi ile gerçekleştirilecek politikalar kapsamında biyofilinin teoride kalmayarak, uygulanmış projelerin ülkemizde de görüleceği ve sayısının arttacağı düşünülmektedir. İmrahor Vadisi gibi benzer nitelikte doğal alanların korunması adına peyzaj mimarları ve diğer meslek gruplarının planlama ve tasarım alanında biyofiliyi temel alan ortak çalışmalar yürütülmeli, biyofilik planlama kararları ve tasarım yaklaşımları ele alınmalıdır. Biyofilik planlama ve tasarım sosyal, psikolojik, ekonomik, turizm, sağlık, çevre gibi farkl1 konular ve farklı meslek disiplinleriyle çalışılarak ülke ölçeğinde uygulanabilirliği daha kapsamlı bir şekilde irdelenmelidir. Daha faydalı peyzaj alanları gerçekleştirebilmek için şehirler biyofilik yaklaşımla planlanmalı ve bütün peyzaj alanlarında biyofilik tasarım yaklaşımları altında incelemeler yapılmalı ve tasarımlar bu yönde gerçekleştirilmelidir.

Çalışma kapsamında kentlinin dış mekandaki gereksinimlerine cevap verebilecek aktif ve pasif etkinliklere olanak tanınmıştır. Rekreasyonel, estetik ve terapik açıdan kullanım uygunluğu, günün stresinden uzaklaşıp ruhsal iyileşme, sosyalleşme olanağı tanıması, flora ve fauna varlığı ile ekosistemin korunması gibi bir çok fayda sağlayacaktır. Aynı zamanda korunması sağlanmış ve biyofilik tasarımların gerçekleşeceği öngörülen, çevreyle uyumlu kentsel turizm faaliyetlerine de katkı sağlayacağı ön görülmektedir. Sunulan önerilerin gerçekleştirilmesi durumunda kentin çekiciliğinin ve tanıtımının önemli miktarda arttacağı beklenmektedir. İmrahor Deresi, Ankara için önemli ekolojik ve su sistemlerindendir. Mevcuttaki dere sslah edilerek genişletilme çalışmalarına gidilmelidir. Ekoloji, doğa koruma ve kullanımı, biyofili ve turizm konularında önemli bir yere sahip olan dere, kentin ekolojik ve su sisteminin önemli bir halkasıdır. 
ÇOMÜ Zir. Fak. Derg. (COMU J. Agric. Fac.)

2021: 9 (1): 71-78

ISSN: $2147-8384$ / e-ISSN: 2564-6826

doi: 10.33202/comuagri.837716

Çizelge 3. Tasarım Öneri Listesi

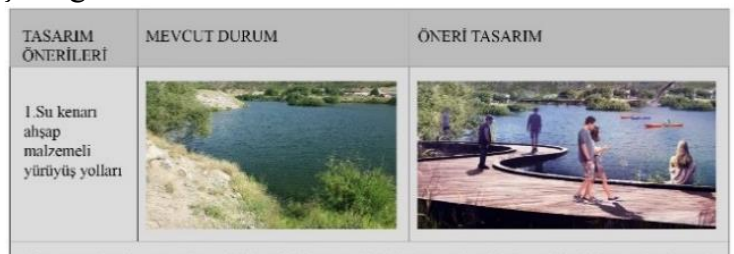

"Suyun varıšs"," suya yakın olabilme fikri insan psikolojisi ve sağlığ için hem biyofili açıınndan hem de

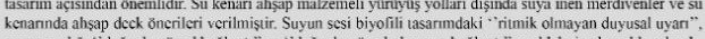

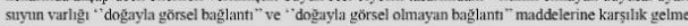
suyun

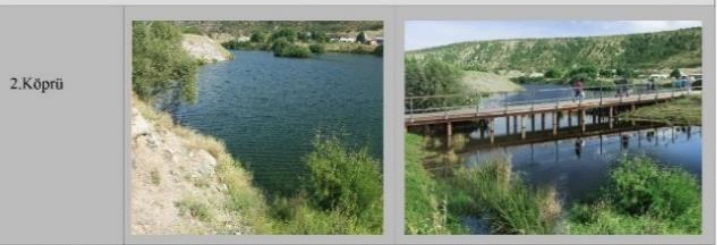

Mevcutlaki alam daha ckkin kullanabilmek adma doğal malıcmeler ile tasarlanmus mevcut doğal dokuya

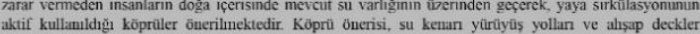
destckleycei tasarm ônerilerindendir.

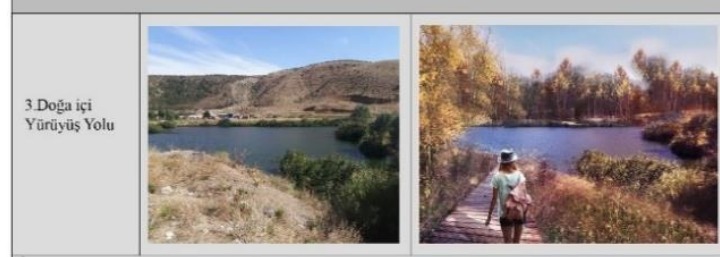

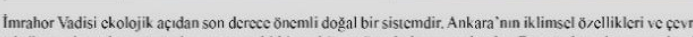

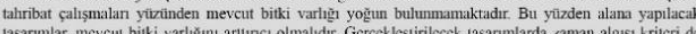

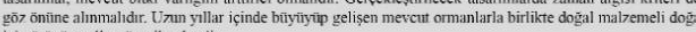

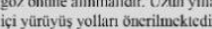

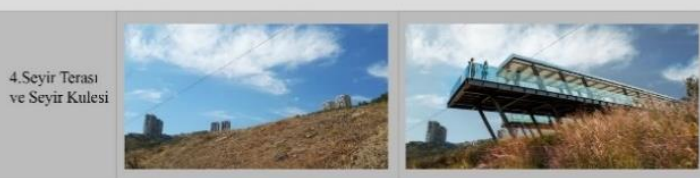

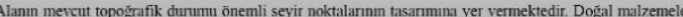
ilc tasarlanacak scyir teraslan dısında scyir kulesi tasarmm ôncrileri de verilmckicdiri insanoğlunum urnanma,

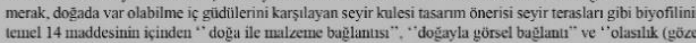

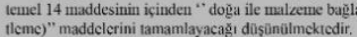

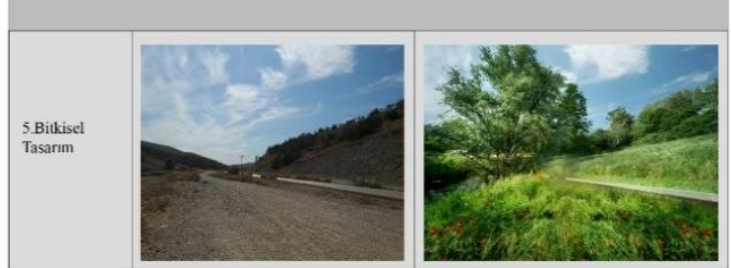

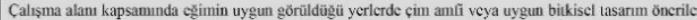
getirilmektedir. Mevcut topoğrafyaya uygun olarak yapllan ōneri tasarnmlann, doğayy konuması ve uygun kullamlmass açssmdan Onemli bulummustur Calsıma alumu icerisinde yol kenarlarlannda ve eşimli alaullarda.

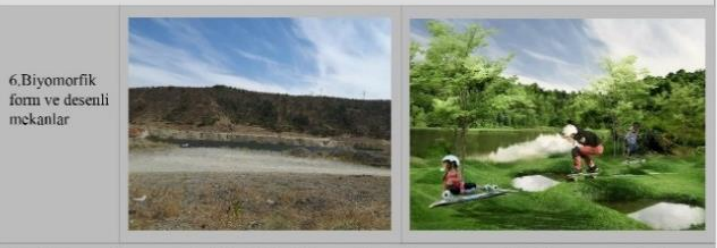

Biyofilinin ōnemli parametrelerinden biri de "biyomorfik formlar ve desenler" dir. Bu parametre, doğgada var

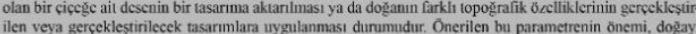
taklit eden ve doğadau ilham alman tasanullara onncü olmakladır

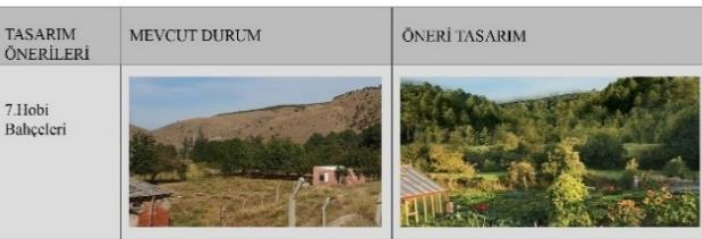

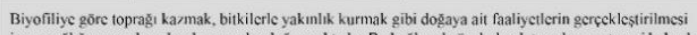

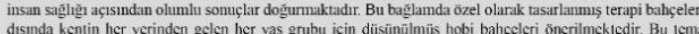

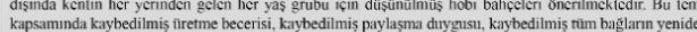

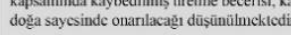

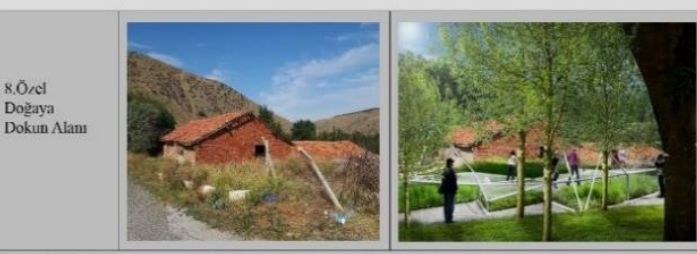

14 maddelik biyofili parameresinin içerisinde yer alan "rimimik olmayan duyusal uyan" parametresine ơmck olarak özel doğaya dokun alanı ônerisinde bulunulmaktadir. Kamusal alanlarda da doğa ile yakın temasta b likte asarianan bilkicel tass dir. Buradaki amaç kalabalik içerisinde de kendini dọ̆ayay yakn hissetmek olmuștur.

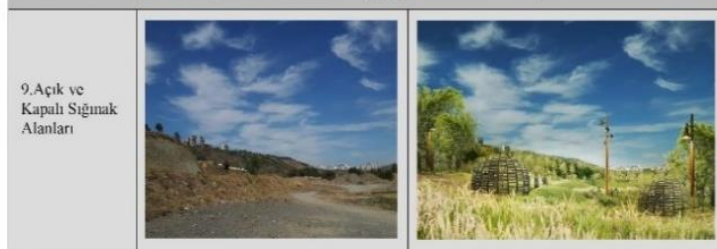

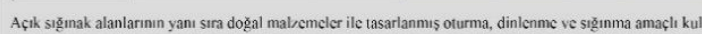

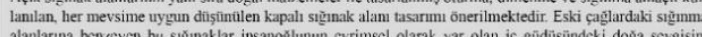

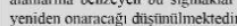

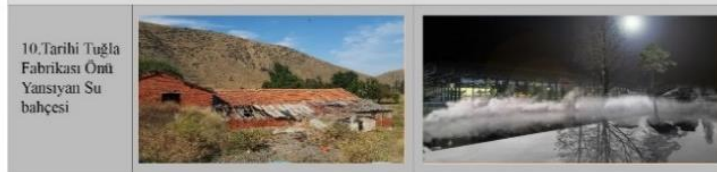

Bireylerin doğă ile iç içe olduklan tasanmlardun sonra sembolik olarak bir kaç tasanma ihtivac vardur

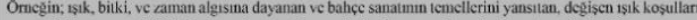
na, sicaklik ve nemdeki dalgalanmalara, yağị̧a ve buharlaşmaya duyarlı olan atmosferik bir yansıyan siu bahçesi tasarnu önerilmekledir. Suyla dolu olan tasarmm, cevresindeki dog̣amu var olan güeelliklerin

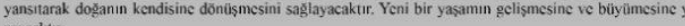

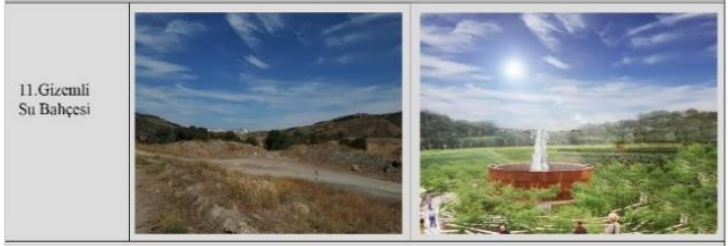

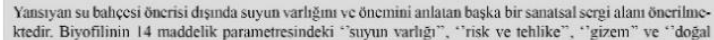
kedir. Biyonilinin 14 maddelik parametresind

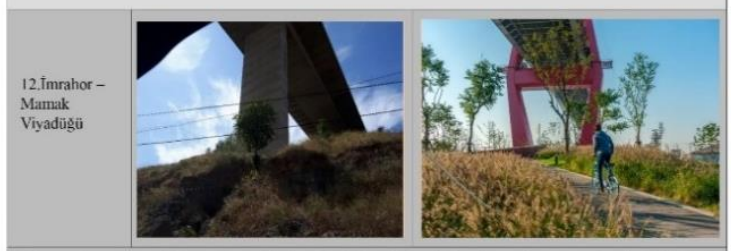

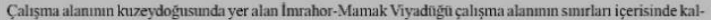

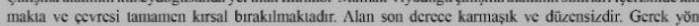
lendime bilgilendirme tabelalannın eksikligi gerek aydılatma elemanlarnin tehlikeli oluşu alanda yeni bir

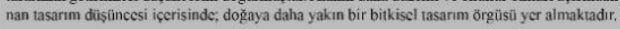

Dere potansiyelinin arttırılması ve ülkesel, bölgesel ve yerel olarak tanıtılması teşvik edilmelidir. Su kenarı doğal malzemeli yürüyüş yolları, doğa içi yürüyüş yolları, köprü, seyir terası ve seyir kulesi, bitkisel tasarım, biyomorfik form ve desenli mekanlar, hobi bahçeleri, özel doğaya dokun 
alanı, açık ve kapalı sığınak alanları, tarihi tuğla fabrikası önü yansıyan su bahçesi, gizemli su bahçesi, İmrahor-Mamak viyadüğü Çizelge 3'de Tasarım Öneri Listesi'nde mevcut durum ve öneri tasarım alanları ile birlikte açıklamalarına yer verilmiştir. Liste dışında çalışma alanına bakıldığında henüz bireylerin kullanımına açık bir yer değildir. Geçici bir kaç aktive alanı dışında sürekli bir aktive alanına rastlanılmamıştır. İmrahor Vadisi'ne yönelik gerçekleştirilen tasarım önerilerinden biri de çocuk oyun alanları olmuştur. Burada dikkat edilen kriter çocuk oyun alanlarının tamamen doğal malzemelerden, ahşap görünümlü bir malzeme değil, gerçek bir ağaç kütüğünden yapılmış oyuncakların kullanılması olmuştur. İlerleyen teknoloji ile doğadan bağı kopmuş çocukların yeniden kopan bağlarını iyileştirmek adına tırmanabilecekleri, temiz oksijen alabilecekleri, oynarken aynı zamanda öğrenebilecekleri alanların tasarımı önerilmektedir.

Tedavi edici olarak kabul edilen "doğanın" iyileştirici gücünden yararlanmak adına İmrahor Vadisi'nde bir bahçe tasarımı önerilmektedir. Önerilen bahçe herhangi bir aktivite alanından uzak, bireylerin kendilerini iyi hissetikleri, bitkiler ile uğraşabilecekleri ve gerekli aktiviteleri yapabilecekleri bir terapi bahçe türüdür. Öneri terapi bahçesi gizli tasarlanmış bir konumdadır. Terapik gizli bahçe, biyofilinin ''gizem", 'karmaşık ve düzen',, 'doğal sistemlerle bağlantı", "'ritmik olmayan duyusal uyarı", "termal ve hava akışı değişkenliği', "doğayla görsel olmayan bağlantı", gibi pek çok maddesini karşılamaktadır.

Biyofiliye göre doğada spor yapan insanların kapalı alanlarda spor yapan insanlara göre daha sağliklı, daha mutlu ve daha enerjik hissetikleri yapılan araştırmalarda tek tek kanıtlanmıştır. Bundan dolayı tüm alanı kapsayan doğa içi yürüyüş yolları, koşu yolları ve bisiklet yolu önerileri getirilmiştir. Tasarım önerileri kapsamında çalışma alanının hemen her noktasında, her alanında görülebilecek kent mobilyaları da önemli bir kriterdir. Oturma- dinlenme elemanları, aydınlatma elemanları, yönlendirme-bildilendirme tabelaları, çöp vb. tamamının doğal malzemeli olmasına dikkat edilmelidir. Bir çok kullanıcıya ev sahipliği yapacağı düşünülen çalışma alanında yeşil bir otopark önerisi getirilmesi de kaçınılmaz olmuştur.

Not: Bu makale birinci yazarın yükseklisans tezinden hazırlanmıştır.

\section{Kaynaklar}

Beatley, T., 2010. Biophilic cities: integrating nature into urban design and planning. What are biophilic cities. Washington. DC: Island Press, 191p.

Browning, W.D., Ryan, C.O. ve Clancy, J.O., 2014. 14 Patterns of biophilic design-improving health \& wellbeing in the built environment. New York: Terrapin Bright Green. LLC., 60p.

Davey, P., 2001. Designing our future. Architectural Review. 209 (1247): 26-27.

Fromm, E. O., 1964. The Heart of man: Its genius for good and evil. Harper\&Row Paper back Edition Publisher. 65p.

Kaya, H., 2019. Biyofilik tasarım ve iyileştiren mimarlık: Çocuk hastaneleri üzerine bir değerlendirme. Gazi Üniversitesi, Fen Bilimleri Enstitüsü, Mimarlık Anabilim Dalı, Yüksek Lisans Tezi, 129s.

Kellert, S. R., 2005. Building for life: Designing and understanding the human- nature connection. Washington, DC: Island Press., 250p.

Kellert, S.R., 1997. Kinship to mastery: Biophilia in human evolution and development Washington. DC: Island Press.

Kellert, S.R., Calabrese, E., 2015. The practice of biophilic design. University of Vermont, Press., 25p.

Khan, J.R., Peter, H., 1997. Developmental psychology and the biophilia hypothesis: Children's affiliation with nature. Developmental Review. 17(1), 1-61.

Öztan, Y., 2004. Yaşadığımız çevre ve peyzaj mimarlığı. Tisamat Basım Sanayi, Ankara.

Şahin, Ş., 1996. Dikmen vadisi peyzaj potansiyelinin saptanması ve değerlendirilmesi üzerine bir araştırma. Ankara Üniversitesi, Fen Bilimleri Enstitüsü, Peyzaj Mimarlığı Anabilim Dalı, Doktora Tezi. 175s.

Tilbury, D., 1995. Environmental education for sustainability: defining the new focus of environmental education in the 1990s. Environmental Education Research. 1(2): 195- 212.

Wilson, E.O., 1984. Biophilia, the Human bond with other species. Harvard University Press, Cambridge (Massachusetts). 157p.

Yılmaz, T., 2008. Büyükesat Vadisi’nin kent peyzajı ve tasarımı kapsamında incelenmesi. Ankara Üniversitesi, Fen Bilimleri Enstitüsü, Peyzaj Mimarlığı Anabilim Dalı, Doktora Tezi. 153s.

Yılmaz, T., 2009. Vadilerde fiziki yapıya bağlı bitkilendirme olanakları, Ankara Büyükesat Vadisi örneği. Ankara Üniversitesi Çevre Bilimleri Dergisi. 1(1). 